\title{
Revision of the genus Macrostomus Wiedemann (Diptera: Empididae: Empidinae). II. The pictipennis species-group
}

José Albertino RAFAEL ${ }^{1} \&$ Jeffrey M. CUMMING ${ }^{2}$

\section{ABSTRACT}

All species of Macrostomus Wiedemann allied with Macrostomus pictipennis (Bezzi), are treated in the pictipennis species-group. Three currently recognized species and four new species are included, namely M. cervicicauda Smith, M. cysticercus Smith, M. manauara, sp. nov. from Brazil (Amazonas and Pará states), M. pacaraima, sp. nov. from Brazil (Roraima, Amazonas and Pará states), M. pictipennis (Bezzi), M. smithi, sp. nov. from Guyana and Brazil (Roraima State) and M. utinga, sp. nov. from Brazil (Pará State). All primary types were examined and a key to species is presented.

KEYWORDS: Amazon Basin, biogeography, Empididae, Macrostomus, taxonomy.

\section{Revisão do gênero Macrostomus Wiedemann (Diptera: Empididae: Empidinae). II. 0 grupo de espécies pictipennis}

\section{RESUMO}

As espécies de Macrostomus Wiedemann afins de Macrostomus pictipennis (Bezzi) estáo sendo tratadas no grupo M. pictipennis, o qual inclui três espécies já descritas e quarto espécies novas, a saber: $M$. cervicicauda Smith, $M$. cysticercus Smith, $M$. manauara, sp. nov. do Brasil (Amazonas e Pará), M. pictipennis (Bezzi), M. smithi, sp. nov. da Guiana e Brasil (Roraima), M. utinga, sp. nov. do Brasil (Pará) e M. pacaraima, sp. nov. do Brasil (Roraima, Amazonas e Pará). Todos os tipos primários foram examinados e uma chave para espécie é apresentada.

PALAVRAS-CHAVE: Amazônia, biogeografia, Empididae, Macrostomus, taxonomy. 


\section{INTRODUCTION}

This paper is the second in a series by the authors that will treat each of the species-groups in Macrostomus Wiedemann. The first paper dealt with the M. ferrugineus species-group, redescribing three species, describing six additional species and discussed the distribution of this Neotropical genus (Rafael and Cumming 2009). Here we diagnose the Macrostomus pictipennis species-group, redescribe three species and describe four additional new species. All these species are distributed in the northwestern Amazonia region (NW Am) as defined by Amorim and Pires (1996), Amorim and Silva (2002) and Amorim (2009), and also depicted in Rafael and Cumming (2009). A key to species for males and females is presented. The $M$. pictipennis species-group appears to be a monophyletic lineage based on the reduction of dorsocentral setae from four to three pairs (except M. pictipennis with four pairs); tergite 8 is modified to an elongate parallel-sided segment with a somewhat blunt apex (most Macrostomus species have a somewhat acute apex); vein $\mathrm{R}_{4+5}$ is distinctly curved medially; the epandrium lacks or has only a shallow anterodorsal sinus; the epandrium usually has highly developed anterodorsal and posterodorsal lobes; the wing in the female is distinctly more infuscated than in the male; the legs in the female have pinnate setae on the flattened hind femur, the hind tibia and generally the mid femur (rarely on the mid tibia); and the genital fork in the female is slender with long lateral arms. Revision of the remaining species of Macrostomus, including descriptions of several new species will be published group by group in the near future. The last paper in the series will include a key to the species-groups and will analyze their phylogenetic relationships.

\section{MATERIAL AND METHODS}

This study is based on the examination of specimens housed in the following institutions: American Museum of Natural History (AMNH), New York, USA; Natural History Museum (BMNH), London, UK; Canadian National Collection of Insects (CNC), Ottawa, Canada; Instituto Nacional de Pesquisas da Amazônia (INPA), Manaus, Brazil; Museu Paraense Emílio Goeldi (MPEG), Belém, Brazil, and Staatliches Museum für Tierkunde (SMTD), Dresden, Germany. Morphological terminology primarily follows Cumming and Wood (2009). Dissection methods, depiction of male terminalia (with epandrium colored gray) and presentation of label data is as stated in Rafael and Cumming (2009).

\section{RESULTS}

\section{DIAGNOSIS OF MACROSTOMUS PICTIPENNIS SPECIES-GROUP}

Male. Eyes dichoptic; frons shining black, very narrow, about one third of the anterior ocellus width; face shining black, slightly wider than frons, notable at dorsal margin because it is slightly gray pruinose; two pairs of ocellar setae, the posterior pair weaker; flagellum bi-segmented. Thoracic chaetotaxy: three pairs of dorsocentrals, rarely 4; one postpronotal stout and two tiny; one supra-alar presutural; one supra-alar postsutural; one postalar strong and one tiny; two notopleurals, the posterior stout; two pairs of scutellars, the outer pair weaker; 3-4 antepronotals; 1-3 tiny proepisternals, rarely absent and rarely as strong as the dorsal thoracic setae; 3-6 katatergitals. Mid tibia with some setae slightly stronger (Fig. 7a). Hind femur with 2-4 long anteroventral setae on distal third (Fig. 7b); hind tibia with 4-6 long dorsal setae; hind tarsomere 1 with 1-2 long dorsal setae (Fig. 7b). Wing distinctly brown infuscated on costal and distal margin, on transversal $\mathrm{r}-\mathrm{m}$ and slightly on dm-cu crossveins (Figs. 1a, 2a, 3a, 5a, 6a); pterostigma slightly darker; veins $M_{1}, M_{2}$ and apex of $A_{1}$ evanescent; cell $\mathrm{dm}$ elongate, somewhat blunt. Terminalia with tergite 8 relatively short (Fig. 6b) to very elongated, somewhat parallel-sided (Fig. 2b). Epandrium with anterodorsal and posterodorsal lobes small (Fig. 6c) to strongly developed (Fig. 3d), notably the posterodorsal one. Hypandrium with variable setae (Figs. 2d, 3e, 5d, 6e, 7e) or no setae (Figs. 1c). Cercus (Fig. 5c) divided into two lobes (see Rafael and Cumming 2004); anterior cercus somewhat modified, with sinus when viewed dorsally, connected anteriorly and medially by a small cercal expansion; posterior cercus with longer anterodorsal setae and generally a bifid distal arm. Phallus (Figs. 1c, 2d, $3 \mathrm{e}, 5 \mathrm{~d}, 6 \mathrm{e})$ as long as hypandrium, with apical portion of endophallus moderately to extensively projected beyond sheath in most species. Ejaculatory apodeme with three (Fig. 5d) or four lamellae (6e).

Female. Eyes dichoptic; frons wider than anterior ocellus width; face narrower than frons, approximately half of anterior ocellus width. Mid and hind femora and hind tibia widened and flattened. Pinnate setae present on mid femur, rarely on mid tibia basoventrally; present on hind femur and hind tibiae (Figs. 1e-f, 4d-e, 5e-f, 6f-g). Hind tarsomere 1 with 1-2 dorsal setae. Wing (Figs. 1g, 2e, 3f, 5g, 6h) wider and more infuscated than in male, with a large stripe at end of cell $\mathrm{dm}$; this cell distinctly wider distally. Tergite 8 (Figs. 1i-j) elongate, slightly shortened when compared 
to respective sternite. Sternite 8 (Figs. 1j-k) usually with median constriction in ventral view. Genital fork with elongate lateral arms and genital chamber membranous (Fig. 11). Spermatheca (Fig. 3g) with a long duct and a rounded capsule.

\section{KEY TO SPECIES OF THE M. pictipennis SPECIES-GROUP (MALES)}

1. Hypandrium strongly extruded from remainder of genital capsule, forming distinct loop (Fig. 1c) . M. cervicicauda Smith

- Hypandrium not extruded from remainder of genital capsule (Figs. 2c, 3c, 4b, 7d)

2. Epandrium (Fig. 6c) not swollen, with small anterodorsal and posterodorsal lobes; tergite 8 short, nearly subquadrate (Fig. 6b); proepisternal setae as strong as dorsal thoracic setae M. smithi, sp. nov.

- Epandrium inflated; tergite 8 more elongate, nearly parallelsided (Figs. 2b, 3b, 4a, 5b, 7c), proepisternal setae weaker than dorsal thoracic setae ... 3 3Fourpairsofdorsocentral setae(Bolivia,Peru)...M.pictipennis(Bezzi)

- Three pairs of dorsocentral setae (North Amazonia area NAm)

4. Posterodorsal lobe of the epandrium higher than anterodorsal lobe (Figs. 2c, 3d) ........................................ 5

- Bothepandrial lobes ending atsameheight (Figs. 4b, 7d) ............6

5. Tergite 8 markedly elongated with small sinus on small protuberance distally (Fig. 2b); hypandrium with apex slender, slightly inward curved (Fig. 2d) ............. M. cysticercus Smith

- Tergite 8 moderately elongated with distinct apical sinus bearing small needle-shaped protuberance inside (Fig. 3b); hypandrium with apex stouter, strongly inward curved (Fig. 3e) ............................................. Manauara, sp. nov.

6. Tergite 8 with large distal expansion, mainly visible laterally (Fig. 7d) M. utinga, sp. nov.

- Tergite 8 without distal expansion in lateral view (Fig. 4b) .. M. pacaraima, sp. nov.

KEY TO SPECIES OF THE $M$. pictipennis SPECIES-GROUP (FEMALES)(female of $M$. utinga sp. nov. is unknown)

1. Hind femur with pinnate setae only ventrally; mid femur with short pinnate setae ventrally at distal half (cf. Fig. 6f) .. M. manauara, sp. nov.

- Hind femur with pinnate setae dorsally and ventrally; mid femur with pinnate setae various

.. 2

2. Mid leg (Fig. 6f): femur with small pinnate setae only ventrally; tibia without pinnate setae

- Mid leg (Figs. 1e, 4d, 5e): femur with pinnate setae dorsally and ventrally; tibia with few small pinnate setae basally and ventrally

.. 4
3. Proepisternal setae as strong as dorsal thoracicsetae

M. smithi, sp. nov.

- Proepisternal setae weaker than dorsal thoracic setae M. cysticercus Smith

4. Mid femur with dorsal pinnate setae shorter than ventral ones (Figs. 4d, 5e)

5

- Mid femur with long dorsal and ventral pinnate setae approximately of the same size (Fig. 1e)... M. cervicicauda Smith 5. Four pairs of dorsocentral setae ......... M. pictipennis (Bezzi) - Three pairs of dorsocentral setae ... M. pacaraima, sp. nov.

\section{Macrostomus cervicicauda Smith (Figs. 1a-m, 8b)}

Macrostomus cervicicauda Smith, 1963: 160, figs. 10, 12; Rafael and Cumming 2004: 446 (citation); Yang et al. 2007: 145 (catalogue).

Diagnosis. Male with hypandrium strongly extruded, with distinct loop, without setae posteriorly; epandrium thin and high. Female mid femur with pinnate setae dorsally and ventrally, mid tibia with few short pinnate setae basally, hind femur and tibia with long pinnate setae dorsally and ventrally.

Redescripton, based on male holotype. Palpus brown. Legs of holotype missing, description of legs based on specimens from northern Brazil, Roraima State: legs shining yellow with apices of mid and hind femora and fore and mid tibiae darker; hind tibia almost entirely black, yellowish on basal one third; mid tibiae with one anterodorsal seta at basal fourth, two posterodorsal at middle third and one slightly stronger posterior setae at middle; hind leg with 3-4 anteroventral at distal third of femur and 4-5 longer dorsal setae on tibia; hind tarsomere 1 with two longer dorsal setae. Wing (Fig. 1a). Halter light brown. Abdomen shining black, yellowish on segments 1-3. Tergite 8 (Fig. 1b) somewhat elongated with a translucent distal expansion. Epandrium (Fig. 1c) not swollen, thin and high with posterodorsal lobe slightly longer than anterodorsal lobe. Anterior cercus (Figs. 1c-d) with thin projection distally; posterior cercus with bifid posterior arm and internal simple protuberance with setae laterally and distally. Hypandrium (Fig. 1c) simple, very elongated with no setae, with basal loop visible externally in undissected specimen, and with pair of distal protuberances. Phallus with apical portion of endophallus extensively projected beyond sheath.

Size. Body length $3.0 \mathrm{~mm}$ (from original description); wing length $3.9 \mathrm{~mm}$.

Female. Mid femur with long pinnate setae dorsally and ventrally; mid tibia with short basal pinnate setae on basal fourth ventrally (Fig. 1e). Hind femur and tibia with long pinnate setae dorsally and ventrally (Fig. 1f). Wing (Fig. $1 \mathrm{~g})$. Abdomen entirely shining black with tergite 1 yellowish laterally. Sternites 1-7 (Fig. 1h). Segments 8, 9+10 and cercus (Figs. 1i-k); apex of tergite 8 and base of tergite $9+10$ with 
distinct sinus (Fig. 1i); sternite 8 with distinct depression medially. Genital fork (Fig. 11) sclerotized, slender with long lateral arms; genital chamber membranous.

Egg. Oval (Fig. 1m).

Geographical distribution. Guyana, Brazil (Roraima, Amazonas and Pará states), Fig. 8b.

Material. BRITISH GUYANA (sic!), Essequibo River, Moraballi Creek, dark forest, 27.ix.1929, (Holotype $\hat{o}$ and Allotype + , same pin, in copula, BMNH).

Other specimens. BRASIL, Roraima, Rio Uraricoera, Ilha de Maracá, 05-15.x.1987, L.S. Aquino, arm. Malaise (19 INPA); Roraima, Serra Pacaraima, BV-8, 27.viii.1987, J.A. Rafael, E. Bindá \& A.L. Henriques, flor de Heliconia sp (19 INPA); Roraima, Serra Pacaraima, BR 174, 042704N 610756W, 800 m, 01-07.x.1995, J.A. Rafael, A.L.Henriques

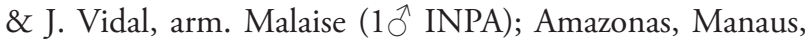
PDBFF/WWF, Proj. Bert Klein, ix.1985, Res. 1208 (10 1 ㅇ INPA); Manaus, F. Esteio, BR 174, km 64, ZF3, 08-10. vi.1993, F.F. Xavier (1 1 1ㅇ INPA, same pin); Manaus, F. P. Alegre, BR 174, km 68, 17-21.i.1984, F.F. Xavier (10 1 우 CNC, same pin); Manaus, Faz. Dimona, BR 174, km 80,

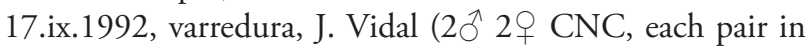
the same pin; $1 \hat{\delta} 1$ 을 INPA, same pin); Amazonas, Parque Nacional do Jau, Joca, 18.x.1993, J. Vidal (1 $\overbrace{}^{\lambda}$ INPA); Amazonas, Rio Carabinani, 16.iv.1994, Malaise, Ruth \& Ricardo (1 9 CNC); Amazonas, Ig. Miratucu, Ig. do Gerlei, 015700S - 614900W, 23-28.vii.1995, arm. Malaise, J.A. Rafael \& J. Vidal (2ᄋ CNC); Pará, Rio Trombetas, Remanso do Inferno, 12.iv.1985, arm. luz, J.E. Bindá (10َ INPA); 14.iv.1985 (2ᄋ INPA).

Holotype condition. Right antenna, right wing and legs missing. Left wing mounted on microslide; terminalia in glycerin in vial beneath specimen.

Variation. Body length varying from $3.8-4.4 \mathrm{~mm}$ [holotype $3.0 \mathrm{~mm}$ ], wing from $3.9-4.5 \mathrm{~mm}$. [holotype wing length $3.9 \mathrm{~mm}$ ]; Wing with weaker brown infuscation in specimens from Amazonas and Pará states.

Discussion. Male specimens of M. cervicicauda are easily separated from all other species of the pictipennis species-group by the hypandrium being strongly extruded as a distinct loop, without setae posteriorly. The female is similar to that of M. pictipennis and M. pacaraima on the basis of the mid femur having pinnate setae dorsally and ventrally, the mid tibia having a few short pinnate setae basally, the hind femur having long pinnate setae dorsally and ventrally, but differs from both in having the mid femur with dorsal and ventral pinnate setae of approximately of the same size. Macrostomus

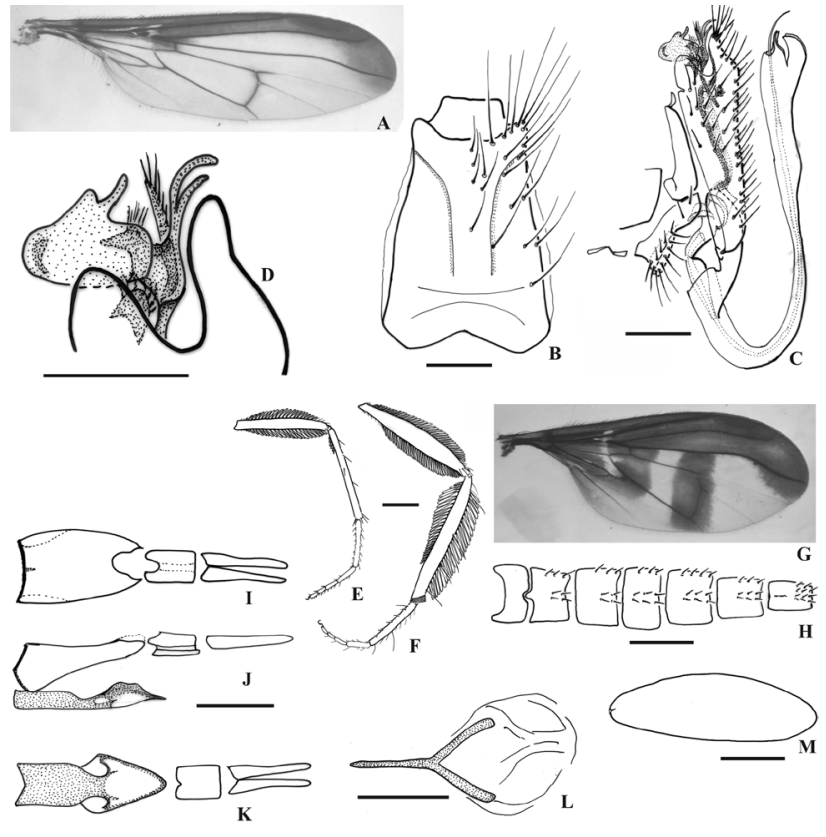

Figure 1 - Macrostomus cervicicauda Smith. A-D, male from Manaus, Brazil. $A$, wing; $B$, tergite 8 , dorsal view with right setae omitted; $C$, terminalia, lateral view; D, detail of posterior circus; E-M, female from Manaus, Brazil. E, mid leg, posterior view; $F$, hind leg, posterior view; $G$, wing; $H$, sternite $1-7$, ventral view with left setae omitted; I-K, tergite $8,9+10$ and cercus, dorsal, lateral and ventral view respectively; L, genital fork, ventral view; M, egg. Scales: E-F $=0.5 \mathrm{~mm} ; \mathrm{C}, \mathrm{H}-\mathrm{K}=0.2 \mathrm{~mm} ; \mathrm{B}, \mathrm{D}, \mathrm{L}-\mathrm{M}=0.1 \mathrm{~mm}$

pictipennis and M. pacaraima have dorsal pinnate setae shorter than the ventral ones.

\section{Macrostomus cysticercus Smith (Figs. 2a-e, 8b)}

Macrostomus cysticercus Smith, 1963: 158; 1967: 30 (catalogue); Rafael and Cumming 2004: 446 (citation); Yang et al. 2007: 145 (catalogue).

Diagnosis. Male tergite 8 elongated with small sinus on small protuberance distally and with series of small short spines subapically; epandrium swollen with strong posterodorsal lobe longer than anterodorsal one; hypandrium with apex bifid, somewhat inward curved. Female mid femur with short pinnate setae ventrally, hind femur with short pinnate setae dorsally and ventrally.

Redescription, based on holotype male. Palpus yellow. Legs shining yellow with apices of mid and hind femora and fore and mid tibiae darker; hind tibia slightly darker on distal third. Mid tibiae with some setae slightly stronger, one anterodorsal at basal fourth, one posterodorsal, one posterior near middle and 2-3 ventral along distal third; hind femur with two anteroventral at distal third distinctly longer; hind tibia with 5-7 longer dorsal setae; hind tarsomere 1 with two longer dorsal setae. Wing (Fig. 2a). Halter light brown. 
Abdomen shining yellow to light brown. Tergite 8 (Fig. 2b) elongated with small sinus on small protuberance distally and short spiniform setae subapically. Epandrium (Fig. 2c) swollen with strong posterodorsal lobe longer than anterodorsal lobe. Anterior cercus small (Fig. 2c); posterior cercus with simple posterior arm and very long curved internal protuberance with setae distally. Hypandrium (Fig. 2d) with setae medially, almost reaching apex and with elongated, inward curved and paired distal protuberance. Phallus with apical portion of endophallus moderately projected beyond sheath. Ejaculatory apodeme with developed dorsal lamella.

Size. Body length $3.7 \mathrm{~mm}$; wing length $3.5 \mathrm{~mm}$.

Female. Mid and hind femora yellow, hind tibia slightly darker than in male. Pinnate setae present ventrally on distal half of mid femur; on median third dorsally and distal half ventrally of hind femur; on entire dorsal and basal two thirds ventrally of hind tibia. Wing (Fig. 2e). Abdomen shining yellow, tergites slightly darker than sternites. Tergite 8 similar to Figs. 3h-i of M. manauara, somewhat shortened when compared to sternite 8 . Genital fork sclerotized, slender with long lateral arms; genital chamber membranous.

Size: Body length $3.7 \mathrm{~mm}$; wing length $3.4 \mathrm{~mm}$.

Geographical distribution. Trinidad, Guyana, Brazil (Roraima and Amazonas states), Fig. 8b.

Material. BRITISH GUYANA (sic!), Kaieteur, high forest,

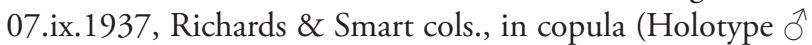
and Allotype + BMNH); Paratypes: same data as holotype, in copula (1 1 1ㅇ BMNH); savannah, 05.ix.1937, Richards $\&$ Smart cols. $(2 \lesssim 2 q$ BMNH).

Other specimens. TRINIDAD, Morne Blue, 2700', 06.viii.1969, H. \& A. Howden (1우 CNC); Arima,

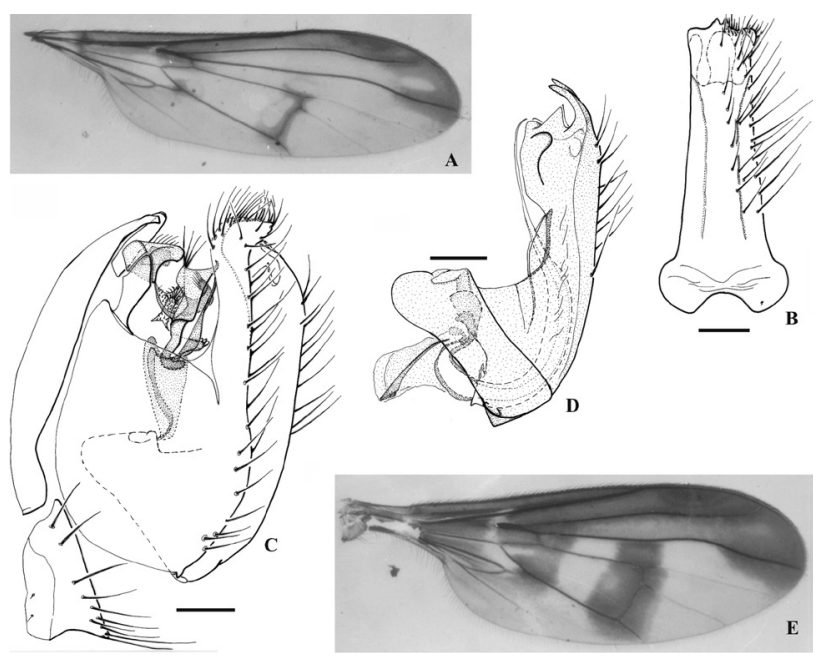

Figure 2 - Macrostomus cysticercus Smith, from Manaus, Brazil. A-D, male; $A$, wing; $B$, tergite 8 , dorsal view with right setae omitted; $C$, terminalia, lateral view; $D$, hypandrium, lateral view. $E$, female wing. Scales: $B-D=0.2 \mathrm{~mm}$.
Blanchicheuse Rd., 2000', Feb. 01-06.1982, Norton S. Adams

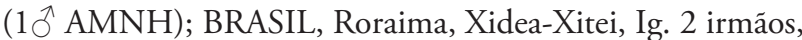
16-29.iii.1996, F. Fernandez, arm. Malaise (2 $\overbrace{}^{\Uparrow}$ INPA, both in glycerin); Amazonas, Manaus, Res. Ducke, 11.v.1989, J.A. Rafael \& Socorro Rosa, flor de Miconia nervosa (2§ INPA, in glycerin; 1 I INPA).

Holotype condition. Good. Left antenna missing.

Variation. Body length varying from $3.5-3.8 \mathrm{~mm}$.

Discussion. Male specimens of $M$. cysticercus differ from other species of the pictipennis species-group in having a long and somewhat slender tergite 8 with a subapical series of small short spines and a small distal sinus, and a hypandrium with the apex somewhat inwardly curved. The female is similar to that of M. smithi in having the mid femur with short pinnate setae ventrally and the hind femur with short pinnate setae dorsally and ventrally, but differs in having weaker proepisternal setae than dorsal thoracic setae.

\section{Macrostomus manauara, sp. nov. (Figs. 3a-I, 8b)}

Diagnosis. Male tergite 8 with invaginated narrow distal sinus bearing small spiniform protuberance inside; epandrium with strong posterodorsal lobe, longer than anterodorsal one; hypandrium with strong inward curved paired distal protuberance. Female hind femur with pinnate setae ventrally.

Description. Holotype male. Palpus yellow. Legs shining yellow with apices of mid and hind femora and fore and mid tibiae darker; hind tibia black on distal third. Mid tibia with one posterior setae at basal fourth, one posterodorsal, one posterior slightly stronger setae at middle; hind femur with 3-4 anteroventral stronger setae on distal third; hind tibia with 4-5 longer dorsal setae; hind tarsomere 1 with one longer dorsal seta. Wing (Fig. 3a). Halter light brown. Abdomen almost entirely shining yellow; terminalia also predominantly yellow, darker at apex. Tergite 8 (Fig. 3b) elongated with narrow distal sinus bearing small protuberance within distal sinus and with series of small spiniform setae subapically. Epandrium (Figs. 3c-d) swollen with strong posterodorsal lobe, longer than anterodorsal lobe. Anterior cercus small (Fig. 3c); posterior cercus with bifid posterior arm and long curved internal protuberance with setae distally. Hypandrium (Fig. 3e) with setae medially and with inward curved and paired apex. Phallus with apical portion of endophallus moderately projected beyond sheath. Ejaculatory apodeme with developed dorsal lamella.

Size. Body length $3.8 \mathrm{~mm}$; wing length $3.9 \mathrm{~mm}$.

Female. Pinnate setae present ventrally on mid femur on distal third, on hind femur ventrally on distal half, and on hind tibia entirely dorsally and ventrally along basal half. Wing (Fig. 3f). Abdomen yellow; position of spermatheca internally as in Fig. 3g; terminalia black. Tergite 8 somewhat shortened when compared to sternite 8 (Figs. 3h-i). Sternite 8 (Fig. 3j) wider on distal half. Genital fork (Fig. 3k) sclerotized, slender with 
long lateral arms; genital chamber membranous. Spermatheca (Fig. 31) with long duct and rounded capsule.

Size. Body length $3.6 \mathrm{~mm}$; wing length $3.8 \mathrm{~mm}$.

Geographical distribution. Brazil (Amazonas and Pará states), Fig. 8b.

Material. Holotype $\widehat{\delta}$ : BRASIL, Amazonas, Manaus, F[azenda] Esteio, BR 174, km 64, ZF3 // 08-10.vi.1993, F.F.Xavier, varredura (INPA).

Paratypes. Same data as holotype $(1 \hat{\delta} 1 \uparrow$ INPA, same pin); Manaus, F. P. Alegre, BR 174, km 68, 17-21.i.1994, F.F. Xavier (3ðै2 2 CNC); Manaus, Res. Ducke, 20.vii.1988, J.A.

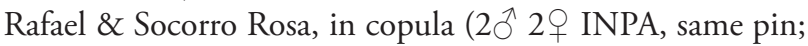

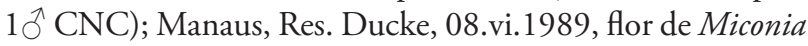
nervosa (1오 CNC); Presidente Figueiredo, 25-30.iii.1996, F.F. Xavier (19 INPA); Pará, Rio Trombetas, Cruz Alta, 2528.vii.1992, arm. Malaise, J. Vidal (1へ̂ INPA); Pará, Rio Mapuera, margem direita, Cach. Assunção, 17.vi.1986, Eq. Baracuxi, Malaise (20 INPA); Rio Mapuera, 05-17.vi.1986, Eq. V. Py-Daniel (1 $\widehat{\partial}^{\lambda} 1$ ㅇ CNC).

Holotype condition. Good, not dissected

Etymology. Named from the Amazonian word for the natives of Manaus where most of the specimens were collected.

Variation. Body length varying from $3.5-3.9 \mathrm{~mm}$. Some paratypes with abdomen darker on posterior tergites.

Discussion. Macrostomus manauara appears most closely related to $M$. pacaraima on the basis of male tergite 8

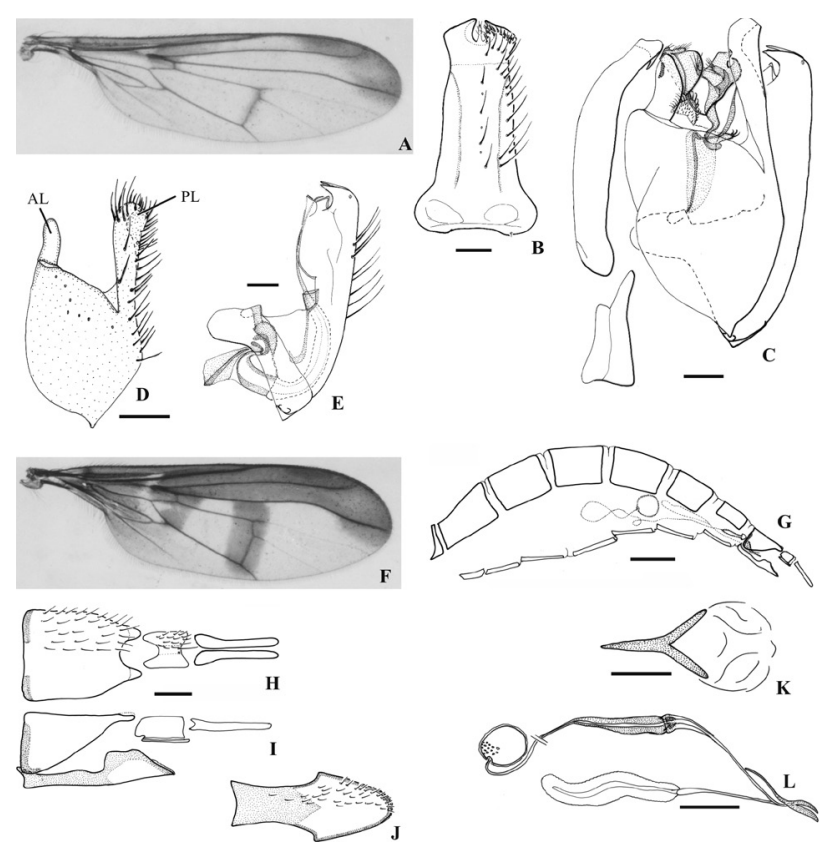

Figure 3 - Macrostomus manauara, sp. nov., paratype from Manaus. A-E, male; $A$, wing; $B$, tergite 8 , dorsal view with right setae omitted; $C$, terminalia, lateral view; D, epandrium, lateral view; E, hypandrium, lateral view. F-L: female; F, possessing an invaginated narrow distal sinus and a series of small spiniform setae subapically. Macrostomus manauara differs from $M$. pacaraima in the presence of a small needleshaped protuberance inside the sinus. Female specimens of M. manauara differ from all other species of the pictipennis species-group in only having pinnate setae on the ventral surface of the hind femur.

\section{Macrostomus pacaraima, sp. nov. (Figs. 4a-h, 8b)}

Diagnosis. Male tergite 8 with invaginated narrow distal sinus and series of small spiniform setae subapically; epandrium swollen with strong posterodorsal lobe ending at same height as anterodorsal lobe. Female mid femur with pinnate setae dorsally and ventrally, mid tibia with few short pinnate setae basally, hind femur and tibia with long pinnate setae dorsally and ventrally.

Description. Holotype male. Palpus brown. Legs shining yellow with apices of mid and hind femora and fore and mid tibiae darker; hind tibia almost entirely black, yellowish on basal fourth. Mid tibiae with some setae slightly stronger, one anterodorsal, one posterodorsal at basal fourth and one posterodorsal near middle; hind femur with 2-3 anteroventral setae on distal third; hind tibia with 4-6 longer dorsal setae; hind tarsomere 1 with two longer dorsal setae. Wing with typical pattern of the species-group described above. Halter light brown. Abdomen shining black, with segments 1-2 and epandrium yellowish. Tergite 8 (Fig. 4a) elongated with narrow distal sinus and series of small spiniform setae subapically. Epandrium (Fig. 4b) swollen with strong posterodorsal lobe ending at same height as anterodorsal lobe. Anterior cercus (Fig. 4b) somewhat large; posterior cercus with bifid posterior arm and very long curved internal protuberance with setae on distal third. Hypandrium (Fig. 4c) with setae medially, almost reaching apex, and with short distal unpaired protuberance. Phallus with apical portion of endophallus moderately projected beyond sheath. Ejaculatory apodeme with developed dorsal lamella.

Size. Body length $3.5 \mathrm{~mm}$; wing length $3.6 \mathrm{~mm}$.

Female. Mid femur with pinnate setae present dorsally and ventrally; mid tibia with few small pinnate setae on basal fourth ventrally (Fig. 4d). Hind femur and tibia (Fig. 4e) with pinnate setae dorsally and ventrally. Abdomen entirely shining black. Tergite 8 (Fig. 4f-g) somewhat shortened with distal sinus. Tergite 9+10 (Fig. 4f) short with basal sinus. Sternite 8 as in figs. 4g-h. Genital fork sclerotized, slender with long lateral arms, similar to Fig. $1 \mathrm{~h}$ of $M$. cervicicauda; genital chamber membranous.

Size. Body length $3.6 \mathrm{~mm}$; wing length $3.8 \mathrm{~mm}$.

Geographical distribution. Brazil (Roraima, Amazonas and Pará states), Fig. 8b. 
Material. Holotype $\overbrace{}^{\Uparrow}$ : BRASIL, Roraima, Serra Pacaraima, BR 174, 042704N -610756W // 800 m, 01-07.ix.1995, J.A. Rafael, A.L. Henriques \& J. Vidal, arm. Malaise (INPA).

Paratypes. Same data as holotype $(1 \delta 1$ INPA, $1 \delta 1$ 우 CNC); Roraima, Serra Pacaraima, 25.iv-05.vii.1988, Eq. J.A. Rafael, arm. Malaise ( $1 q \mathrm{CNC})$; Amazonas, S. Gabriel da Cachoeira, Morro 6 Lagos, 28.ix.-06.x.1990, arm. Malaise, J.A. Rafael \& J. Vidal (1ð̂ $1 q$ INPA); Amazonas, S. Izabel do Rio Negro, Maturacá, 11-13.x.1990, arm. Malaise, J.A. Rafael (1 $\left.\sigma^{1} \mathrm{CNC}\right)$; Amazonas, Manaus, BR 174, km 72, Faz. Dimona, 11-14.v.1993, F.F. Xavier, varredura (1ठ 1 q INPA, same pin); Amazonas, Rio Nhamundá, 01³5'11"S 57³7'34”W, 17-20.v.2008, J.A. Rafael e equipe, Malaise 1 ㅇ INPA; Pará, Rio Trombetas, Remanso do Inferno, 14.iv.1985, Malaise, J. Bindá (1へ̃ INPA).

Holotype condition. Good, not dissected

Etymology. The noun in apposition refers to the place where the species was collected, Serra Pacaraima, Roraima State.

Variation. Body length varying from 3.5-3.8 mm. Some paratypes with hind tibia darker only on distal third and tergite 1 slightly yellow laterally.

Discussion. Macrostomus pacaraima appears close to $M$. manauara on the basis of male tergite 8 bearing an invaginated narrow distal sinus and a series of small spiniform setae

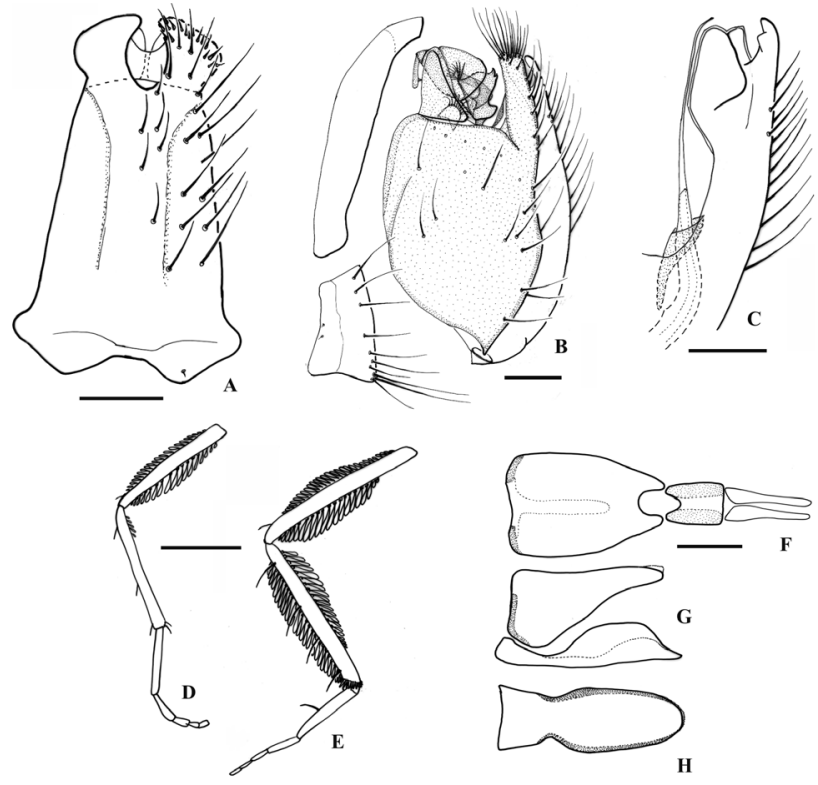

Figure 4 - Macrostomus pacaraima, sp. nov., paratypes from Pacaraima, Brazil. A-C, male; A, tergite 8, dorsal view, right setae omitted; B, terminalia, lateral view; $\mathrm{C}$, apex of hypandrium, lateral view; $\mathrm{D}-\mathrm{H}$, female; $\mathrm{D}$, mid leg, posterior view; E, hind leg, posterior view; F, tergites $8,9+10$ and cercus, setae omitted, dorsal view; $\mathrm{G}$, tergite and sternite 8, setae omitted, lateral view; $\mathrm{H}$, sternite 8, setae omitted, ventral view. Scales: A-B, F-G $=0.5 \mathrm{~mm} ; \mathrm{C}-\mathrm{E}, \mathrm{H}-\mathrm{J}=0.2 \mathrm{~mm}$ subapically. It differs by the absence of the small needle-shaped protuberance inside the sinus that is present in $M$. manauara. The apex of the hypandrium is also different in both species. The arrangement of the female pinnate setae is similar to that of $M$. pictipennis, but the latter species has four pairs of dorsocentral setae rather than three pairs.

\section{Macrostomus pictipennis (Bezzi) (Figs. 5a-I, 8b)}

Rhamphomyia pictipennis Bezzi, 1909: 330; Smith 1963: 158 (citation); 1967: 31 (catalogue).

Macrostomus pictipennis; Rafael and Cumming 2004: 446 (citation); Yang et al. 2007: 145 (catalogue).

Diagnosis. Four pairs of dorsocentral setae. Male tergite 8 elongated with distal protuberance somewhat subquadrate in lateral view; epandrium slightly swollen with strong posterodorsal lobe longer than anterodorsal lobe. Female with pinnate setae dorsally and ventrally on mid femur, hind femur and hind tibia; mid tibia with a few short pinnate setae on basal fourth ventrally.

Redescription based on male specimens from Peru (Cuzco). Palpus brown. Four dorsocentral setae. Legs almost entirely shining yellow with apex of hind tibia darker. Mid tibiae with some setae slightly stronger, one anterodorsal at basal fourth; hind femur with 2-3 anteroventral on distal third; hind tibia with 4 longer dorsal setae; hind tarsomere 1 with two longer dorsal setae. Wing (Fig. 5a). Halter light brown. Abdomen shining black, with segments 1-2 yellowish. Tergite 8 (Fig. 5b) elongated, distal protuberance somewhat subquadrate in lateral view (Fig. 5c). Epandrium (Fig. 5c) slightly swollen with strong posterodorsal lobe longer than anterodorsal lobe. Anterior cercus somewhat small (Fig. 5c); posterior cercus with bifid posterior arm and curved internal simple protuberance with setae mainly distally. Hypandrium (Fig. 5d) with setae reaching apex and with distal inward curved unpaired protuberance. Phallus with apical portion of endophallus moderately projected beyond sheath. Ejaculatory apodeme without dorsal lamella.

Size. Body length varying from $3.6-4.0 \mathrm{~mm}$.

Holotype female in poor condition. Redescription based on specimens from Peru (Cuzco). Four dorsocentral setae. Mid leg (Fig. 5e) with one anterodorsal setae at basal fourth, 2-3 posterodorsal along median third of tibia; pinnate setae on femur along almost entire dorsal face and longer pinnate setae along entire ventral face; tibia with few short pinnate setae on basal fourth ventrally. Hind leg (Fig. 5f) with long pinnate setae on femur and tibia dorsally and ventrally. Wing (Fig. $5 \mathrm{~g}$ ). Abdomen entirely shining black with tergite 1 slightly yellow laterally. Tergite 8 (Fig. 5h-i) somewhat shortened when compared to sternite 8 (Fig. 5 j-k); tergite 8 with distinct basal and distal sinus. Genital fork (Fig. 5l) sclerotized, slender with thin lateral arms; genital chamber membranous. 


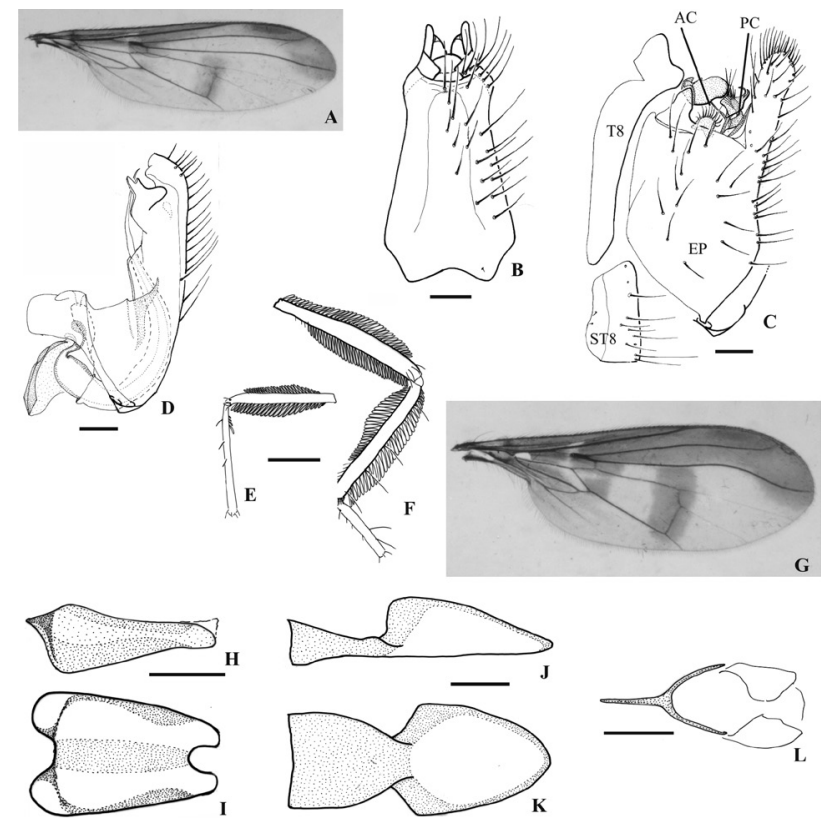

Figure 5 - Macrostomus pictipennis (Bezzi), from Cuzco, Peru. A-D, male; $A$, wing; $B$, tergite 8 , dorsal view, right setae omitted; $C$, terminalia, lateral view; $D$, hypandrium, lateral view. E-L: female. E, mid leg, posterior view; $F$, hind leg, posterior view; G, wing; $\mathrm{H}-\mathrm{I}$, setae omitted; $\mathrm{H}$, tergite 8, lateral view; I, tergite 8, dorsal view; J, sternite 8, lateral view; K, sternite 8, ventral view; L, genital fork, ventral view. Abbreviations: AC, anterior cercus; EP, epandrium; $\mathrm{PC}$, posterior cercus; T8, tergite 8; ST8, sternite 8. Scales: $\mathrm{E}-\mathrm{F}=0.5 \mathrm{~mm}$; $B-D, H-K=0.2 \mathrm{~mm} ; \mathrm{L}=0.1 \mathrm{~mm}$.

Size. From original description, body length $4.0 \mathrm{~mm}$; wing length $4.0 \mathrm{~mm}$.

Geographical distribution. Bolivia and Peru (Fig. 8b).

Material. Holotype 9 : BOLIVIA [La Paz], San Carlos, Mapiri, 08.i.1903, 800 m. (SMTD)

Other specimens. PERU, Cuzco, Quincemil, 13-31.

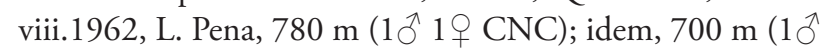
INPA).

Holotype condition. Poor condition. Head squashed, glued to the scutum; antennae, thoracic setae, wings, mid left leg, hind legs and terminalia missing.

Discussion. Macrostomus pictipennis is the only species with four pairs of dorsocentral setae in this species-group and is also the only species recorded to date, from the southwestern Amazonia (SWAm) area (Fig. 8b).

\section{Macrostomus smithi, sp. nov. (Figs. 6a-k, 8b)}

Macrostomus pictipennis; Smith, 1961: 54, figs. 1-4 (misidentification).

Diagnosis. Proepisternal setae as strong as dorsal thoracic setae. Male tergite 8 somewhat short, subquadrate; epandrium not swollen, with slightly developed anterodorsal and posterodorsal lobes. Female mid femur with short pinnate setae ventrally, hind femur with short pinnate setae dorsally and ventrally.

Description. Holotype male. Palpus yellow to light brown. Two-three proepisternal setae as strong as dorsal thoracic setae. Legs shining yellow with apices of mid and hind femora and fore and mid tibiae darker; hind tibia almost entirely black, yellowish on basal fourth. Mid tibia with some setae slightly stronger, one anterodorsal at basal fourth and two posterior along basal half; hind femur with 1-2 anteroventral setae on distal third; hind tarsomere 1 with one longer dorsal setae. Wing (Fig. 6a) with cell $\mathrm{R}_{1}$ partially hyaline. Halter light brown. Abdomen shining black, with segments 1-2 yellowish. Tergite 8 (Fig. 6b) somewhat short with distal sinus. Epandrium (Fig. 6c) not swollen, with small anterodorsal and posterodorsal lobes. Anterior cercus (Fig. 6c) large; posterior cercus (Fig. 6d) smaller than anterior one, bifid with many setae on posterior arm and few setae on simple anterior arm. Hypandrium (Fig. 6e) with rounded apex and a group of setae medially, and expansion apparently surrounding phallus medially. Phallus with apical portion of endophallus barely projected beyond sheath. Ejaculatory apodeme with developed dorsal lamella.

Size: Body length not measured; wing length $3.9 \mathrm{~mm}$.

Female. Mid tibia with one dorsal seta near middle, 2-3 shorter ventral setae along distal half. Small pinnate setae present ventrally on mid femur along distal half (Fig. 6f); dorsally on hind femur on median third, shorter than ventral pinnate setae present on distal half (Fig. 6g); on hind tibiae along dorsal face and ventrally on basal half (Fig. 6g). Wing (Fig. 6h). Abdomen entirely shining black. Sternite 8 (Figs. 6i-j) with small sinus medially, more distinct in lateral view. Genital fork (Fig. 6k) sclerotized; genital chamber membranous.

Size. Body length $3.6 \mathrm{~mm}$; wing length $3.7 \mathrm{~mm}$.

Geographical distribution. Guyana, Brazil (Roraima State), Fig. 8b.

Material. Holotype $\widehat{\sigma}$ and paratype $q$ : BRITISH GUYANA (sic!), Amatuk Falls, Potaro River, 20.viii.1959, L.R.Cole col. (BMNH, same pin).

Paratypes. BRASIL, Roraima, Pacaraima, 25.iv-05. vii.1988, Eq. J.A. Rafael, arm. Malaise (10 2 \% INPA); Roraima, Serra Pacaraima, BR 174, 042704N - 610756W, 800 m, 01-07.ix.1995, J.A. Rafael, A.L. Henriques \& J. Vidal,

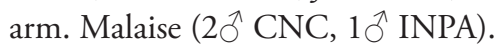

Holotype condition. Left wing mounted on microslide; terminalia in glycerin in vial beneath specimen.

Etymology. The specific name is in honor of Dr. K.G.V. Smith. 
Variation. Body length varying from $3.5-3.8 \mathrm{~mm}$. Some male paratypes with hind femur darker only on distal third, with four long dorsal setae.

Discussion. Male specimens of M. smithi differ from all other species of the pictipennis species-group in having tergite 8 somewhat short and subquadrate, and the epandrium is not swollen and has barely developed anterodorsal and posterodorsal lobes. The female is similar to that of $M$. cysticercus on the basis of the mid femur having short pinnate setae ventrally, and the hind femur having short pinnate setae
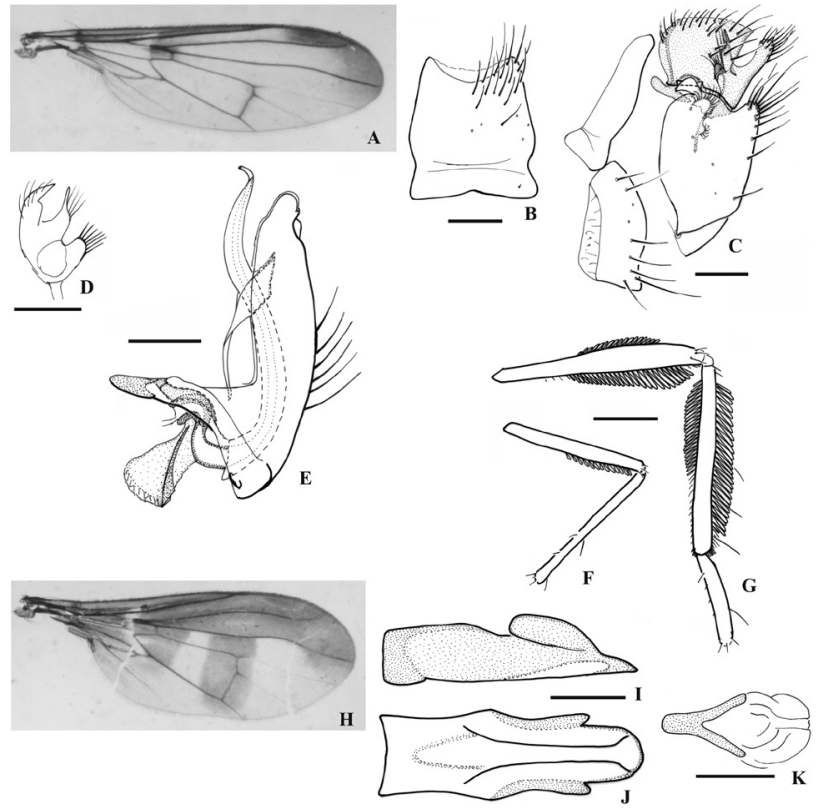

Figure 6 - Macrostomus smithi, sp. nov., A-E, holotype male; A, wing; B, tergite 8, dorsal view, right setae omitted; C, terminalia, lateral view; D, detail of posterior cercus; $\mathrm{E}$, hypandrium, lateral view. $\mathrm{F}-\mathrm{H}$, paratype female. F, mid leg, anterior view; $\mathrm{G}$, hind leg, anterior view; $\mathrm{H}$, wing; I, sternite 8, setae omitted lateral view; J, sternite 8, ventral view; K, genital fork, ventral view. Scales: F-G $=0.5 \mathrm{~mm} ; \mathrm{B}-\mathrm{E}, \mathrm{I}-\mathrm{J}=0.2 \mathrm{~mm} ; \mathrm{K}=0.1 \mathrm{~mm}$.

dorsally and ventrally. It differs from $M$. cysticercus in the proepisternal setae, which are as strong as the dorsal thoracic setae.

\section{Macrostomus utinga, sp. nov. (Figs. 7a-e, 8b)}

Diagnosis. Male tergite 8 with large distal expansion, visible laterally; epandrium with strong posterodorsal lobe; hypandrium with short bifid apex.

Description. Holotype male. Palpus brown. No proepisternal setae. Legs shining yellow with apices of mid and hind femora and fore and mid tibiae darker; hind tibia darker on distal third. Mid tibia (Fig. 7a) with some setae slightly stronger, one anterodorsal at basal fourth, two posterodorsal along median third and one posterior near middle; hind
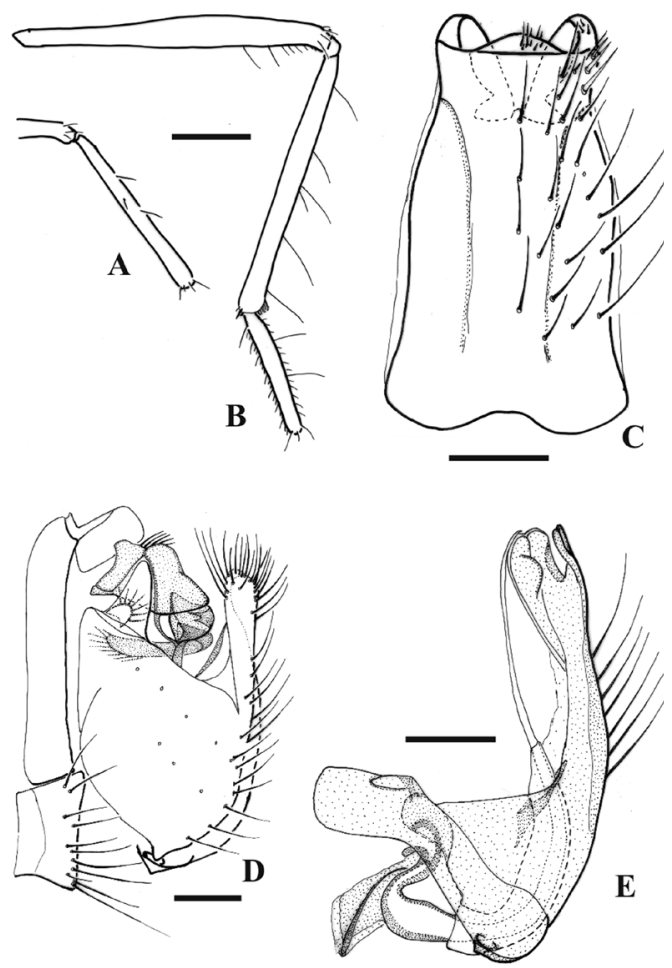

Figure 7 - Macrostomus utinga, sp. nov., holotype male. A, mid leg, posterior view; $B$, hind leg, posterior view; $C$, tergite 8 , dorsal view, right setae omitted; $\mathrm{D}$, terminalia, lateral view; $\mathrm{E}$, hypandrium, lateral view. Scales: $\mathrm{A}-\mathrm{B}=0.5$ $\mathrm{mm} ; \mathrm{C}-\mathrm{E}=0.2 \mathrm{~mm}$.

femur (Fig. 7b) with two anteroventral on distal third; hind tibia with 6-7 longer dorsal setae; hind tarsomere 1 with two longer dorsal setae (Fig. 7b). Wing as in Fig. 1a of $M$. cervicicauda. Halter light brown. Abdomen shining yellow with terminalia darker. Tergite 8 (Fig. 7c) elongated with large ventral projection at apex, distinct in lateral view (Figs. 7d). Epandrium (Fig. 7d) slightly swollen with strong anterodorsal and posterodorsal lobes. Anterior cercus (Fig. 7d) somewhat large; posterior cercus with bifid posterior arm and very long curved internal protuberance with setae on distal third. Hypandrium (Fig. 7e) with group of setae medially and with short bifid apex. Phallus with apical portion of endophallus moderately projected beyond sheath. Ejaculatory apodeme with developed dorsal lamella.

Size: Body length $3.9 \mathrm{~mm}$; wing length $4.1 \mathrm{~mm}$.

Female. Unknown.

Geographical distribution. Brazil (Pará State), Fig. 8b.

Material. Holotype ${ }^{\Uparrow}$ : BRASIL, Pará, Belém, Utinga, 11.iii.1983, S.M. da Silva (MPEG).

Holotype condition. Wings bent; abdomen in glycerin in vial beneath specimen. 

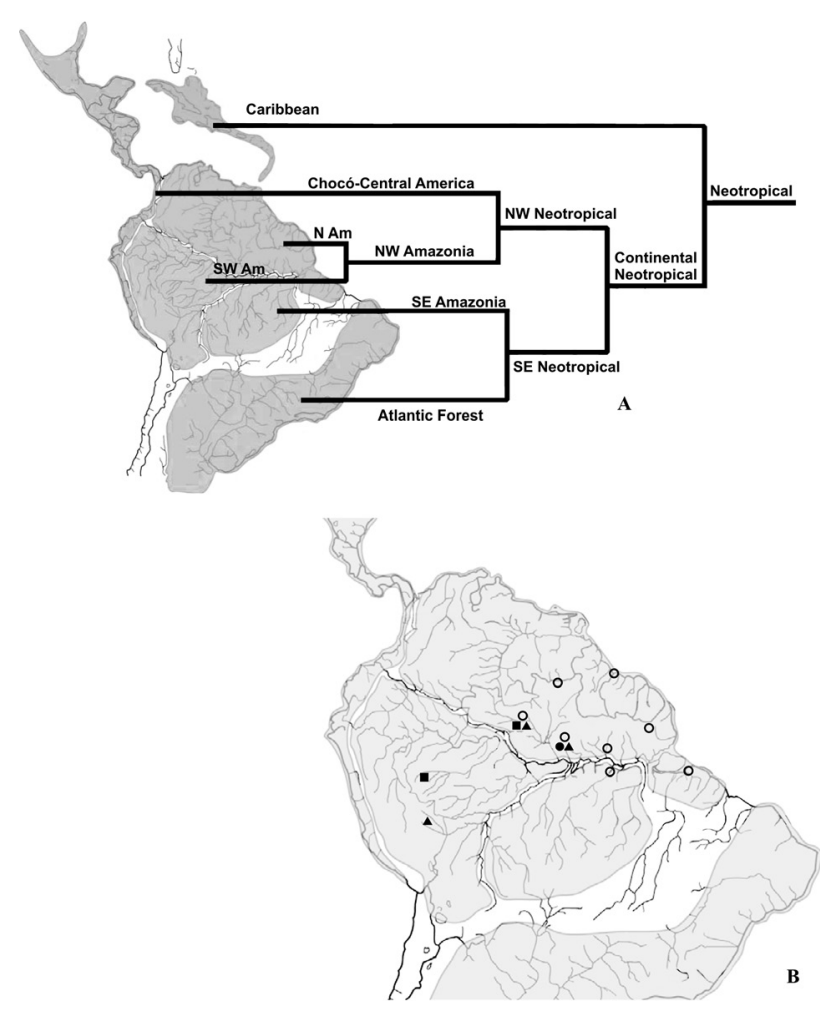

Figure 8 - A, general biogeographic pattern of the northern Neotropical region based on different groups of vertebrates, insects and plants (after Amorim 2009); B, distribution map of species belonging to the Macrostomus pictipennis species-group. Symbols represent the known collection localities as follows: diamond $=M$. cervicicauda; open circle $=M$. cysticercus; open triangle $=$ M. manauara, sp. nov.; square $=M$. pacaraima, sp. nov.; solid triangle $=$ M. pictipennis; star $=$ M. smithi, sp. nov.; solid circle $=$ M. utinga, sp. nov.

Etymology. The noun in apposition refers to the place where the species was collected, Utinga, Belém.

Discussion. Male specimens of $M$. utinga differ from all other species of the pictipennis species-group in tergite 8 having a large distal expansion that is visible laterally, and the hypandrium has a short bifid apex.]

\section{Macrostomus sp}

Two different female specimens belonging to the pictipennis group possess a different wings pattern and a different arrangement of pinnate setae on the legs. They were not associated with males and are therefore not being described at this time.

Material. BRASIL, Roraima, Pacaraima, 25.vi-05. vii.1988, Eq. J.A. Rafael (2ㅇ INPA).

\section{BIOGEOGRAPHICAL PATTERN}

The biogeographic relationships of the continental northern Neotropical region were presented by Amorim
(2009) and their components (Fig. 8a) were briefly described by Rafael and Cumming (2009). All species of the $M$. pictipennis species-group occur in the NWAm area that is further subdivided into North Amazonia (NAm) and Southwest Amazonia (SWAm) (Fig. 8a). Most of the species occur in NAm except for $M$. pictipennis, which occurs in WAm. Apparent confinement of the M. pictipennis speciesgroup to the NWAm area, with different species in both subareas (Fig. 8b) suggests that the evolutionary history of the $M$. pictipennis species-group is similar to that of the $M$. ferriguineus species-group (see Rafael and Cumming 2009) and is largely in agreement with the area cladogram (Fig. 8a) presented by Amorim (2009).

\section{ACKNOWLEDGEMENTS}

We thank the following curators for the loan of specimens: Dr. David Grimaldi (AMNH), Dr. John Chainey (BMNH), Dr. Inocêncio Gorayeb (MPEG) and Dr. Uwe Kalweit (SMTD). Field collections were financed by the Instituto Nacional de Pesquisas da Amazônia (INPA) and the Programa de Apoio a Núcleos de Excelência of the Fundação de Amparo à Pesquisa do Estado do Amazonas (PRONEXCNPq-FAPEAM Edital 016/2006, Proc. 1437/2007). JAR is financially supported by the Conselho Nacional de Desenvolvimento Científico e Tecnológico (CNPq) grant 300305/2007-9.

\section{REFERENCES}

Amorim, D.S. 2009. Neotropical Diptera Diversity: Richness, Patterns, and Perspectives. In: T. Pape, D. Bickel and R. Meier (eds), Diptera Diversity: Status, Challenges and Tools. Brill, Leiden, pp. 71-97.

Amorim, D.S.; Pires, M.R.S. 1996. Neotropical biogeography and a method for maximum biodiversity estimation, In: C.E.M. Bicudo and N.A. Menezes (eds.). Biodiversity in Brazil, a first approach. CNPq, São Paulo, p. 183-219.

Amorim, D.S.; Silva, V.C. 2002. How far advanced was Diptera evolution in the Pangaea? Annales de la Société Entomologique de France (n.s.) 38(1-2): 177-200.

Bezzi, M. 1909. Contribution to the knowledge of the South American Diptera fauna based on the material collected on a journey through Chile, Peru, and Bolivia during the years of 1902-1904 by W Schnuse. Fam Empididae. Nova Acta Academiae Caesareae Leopoldino-Carolinae Germanicae Naturae Curiosorum, Halle, 91(3): 299-406 (in German).

Cumming, J.M.; Wood, D.M. 2009. Adult morphology and terminology [Chapter] 2. In: Brown, B.V.; Borkent, A.; Cumming, J.M.; Wood, D.M.; Woodley, N.E. and Zumbado, M.A. (Eds.): Manual of Central American Diptera, Volume 1, NRC Research Press, Ottawa, Ontario, Canada, p. 9-50.

Rafael, J.A.; Cumming, J.M. 2004. The Neotropical genera Macrostomus Wiedemann and Porphyrochroa Melander (Diptera, 
Empididae, Empidinae). Revista Brasileira de Zoologia 21(3): 439-448.

Rafael, J.A.; Cumming, J.M. 2009. Revision of the genus Macrostomus Wiedemann (Diptera: Empididae: Empidinae). I. The ferrugineus species-group. Zootaxa 2064: 39-56.

Smith, K.G.V. 1961. On the genus Macrostomus Wiedemann (Diptera: Empididae) with notes on the included species and new synonymy. Proceedings of the Royal Entomological Society of London Series B, London 30: 53-56.

Smith, K.G.V. 1963. The Empididae (Diptera) collected on the Oxford University Expeditions to British Guiana in 1929 and
1937. Proceedings of the Royal entomological Society of London (B) 32(9-10): 153-161.

Smith, K.G.V. 1967. Family Empididae (Empidae, Hybotidae) [Part] 39. In: A Catalogue of the Diptera of the Americas south of the United States. São Paulo, Departamento de Zoologia, 67 p.

Yang, D.; Zhang, K.; Yao, G.; Zhang, J. 2007. World Catalog of Empididae (Insecta: Diptera). China Agricultural University Press, Beijing, 599 pp.

Recebido em 14/12/2009

Aceito em 09/03/2010 